Abstracted/indexed in Academic Search Complete, Asia Journals Online, Bangladesh Journals Online, Biological Abstracts, BIOSIS Previews, CAB Abstracts, Current Abstracts, Directory of Open Access Journals, EMBASE/Excerpta Medica, Google Scholar, HINARI (WHO), International Pharmaceutical Abstracts, Open J-gate, Science Citation Index Expanded, SCOPUS and Social Sciences Citation Index;

ISSN: $1991-0088$

\title{
Cytotoxicity study of pyrazole derivatives
}

\author{
Nusrat Binta Ahasan and Md. Rabiul Islam
}

Department of Chemistry, Jahangirnagar University, Savar, Dhaka 1342, Bangladesh.

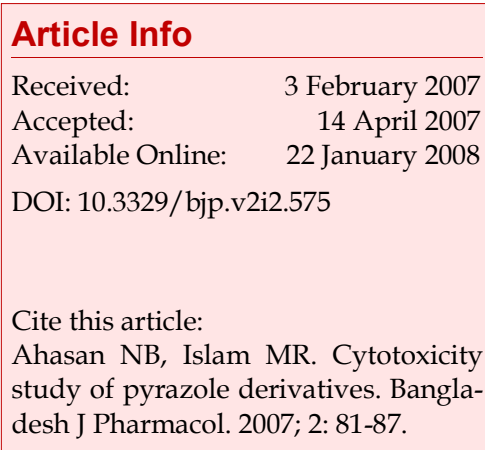

\begin{abstract}
Pyrazolone heterocyclic compound, 3-methyl-1-phenyl-2-pyrazoline-5-one 2 (a) was synthesized by condensation reaction between ethyl acetoacetate and phenyl hydrazine and was converted into their corresponding heterocyclic derivatives $\mathbf{2}(\mathbf{b})$ to $\mathbf{2}\left(\mathbf{f}_{2}\right)$. Their cytotoxicity effects were measured by brine shrimp lethality bioassay. Among them the compounds $\mathbf{2}(\mathbf{b}), \mathbf{2}\left(\mathbf{f}_{1}\right)$, and $\mathbf{2}\left(\mathbf{f}_{2}\right)$ were highly active according to $\mathrm{IC}_{50}$ values $19.5,19.5$ and $20 \mathrm{ppm}$ respectively. The rest of compounds $\mathbf{2}(\mathbf{a}), \mathbf{2}(\mathbf{c}), \mathbf{2}\left(\mathbf{d}_{\mathbf{1}}\right)$, and $\mathbf{2}\left(\mathbf{d}_{\mathbf{2}}\right)$ having $I C_{50}$ values $38,33.5$, $37.5,36,37.5$ and $36 \mathrm{ppm}$ in that order, were moderately active.
\end{abstract}

\section{Introduction}

In confirmation of our work on cytotoxicity of isatin derivatives (Islam and Muhsin, 2007; Islam, 2004) this study on pyrazoles was extended. Pyrazole refers both to the class of simple aromatic ring organic compounds of the heterocyclic series characterized by a 5-membered ring structure composed of three carbon atoms and two nitrogen atoms in adjacent positions and to the unsubstituted parent compound. Being so composed and having pharmacological effects on humans, they are classified as alkaloids, although they are rare in nature. Pyrazoles are used for their analgesic (Gürsoy et al., 2000), anti-inflammatory (Badawey et al., 1998), antipyretic, antiarrhythmic, tranquilizing, muscle relaxing, psychoanaleptic, anticonvulsant, monoamineoxidase inhibiting, antidiabetic and antibacterial activities. Structurally related compounds are pyrazoline and pyrazolidine.

Pyrazole, which is unsubstituted at position 1, exhibits tautomerism. The two tautomeric forms are in rapid equilibrium with each other and the nitrogen atoms are indistinguishable. If pyrazole is tautomeric, then the positions 3 and 5 will be identical. If pyrazole is not tautomeric, then the positions are different. On oxida-<smiles></smiles>

Pyrazole

(1)<smiles>C1=NNCC1</smiles>

Pyrazoline

(2) tion both 3-methyle-1-phenyl pyrazole and 5-methyle-1 -phenyl pyrazole give the same product viz, methyl pyrazole (Finar, 1994). Thus, positions 3 and 5 must be equivalent in pyrazole, and this can only be explained by assuming that pyrazole is tautomeric (1-a) and (1-b).<smiles>c1ccnnc1</smiles>

(1-a)

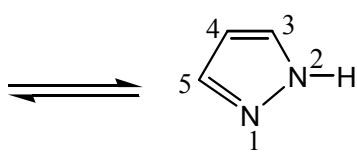

(1-b) 


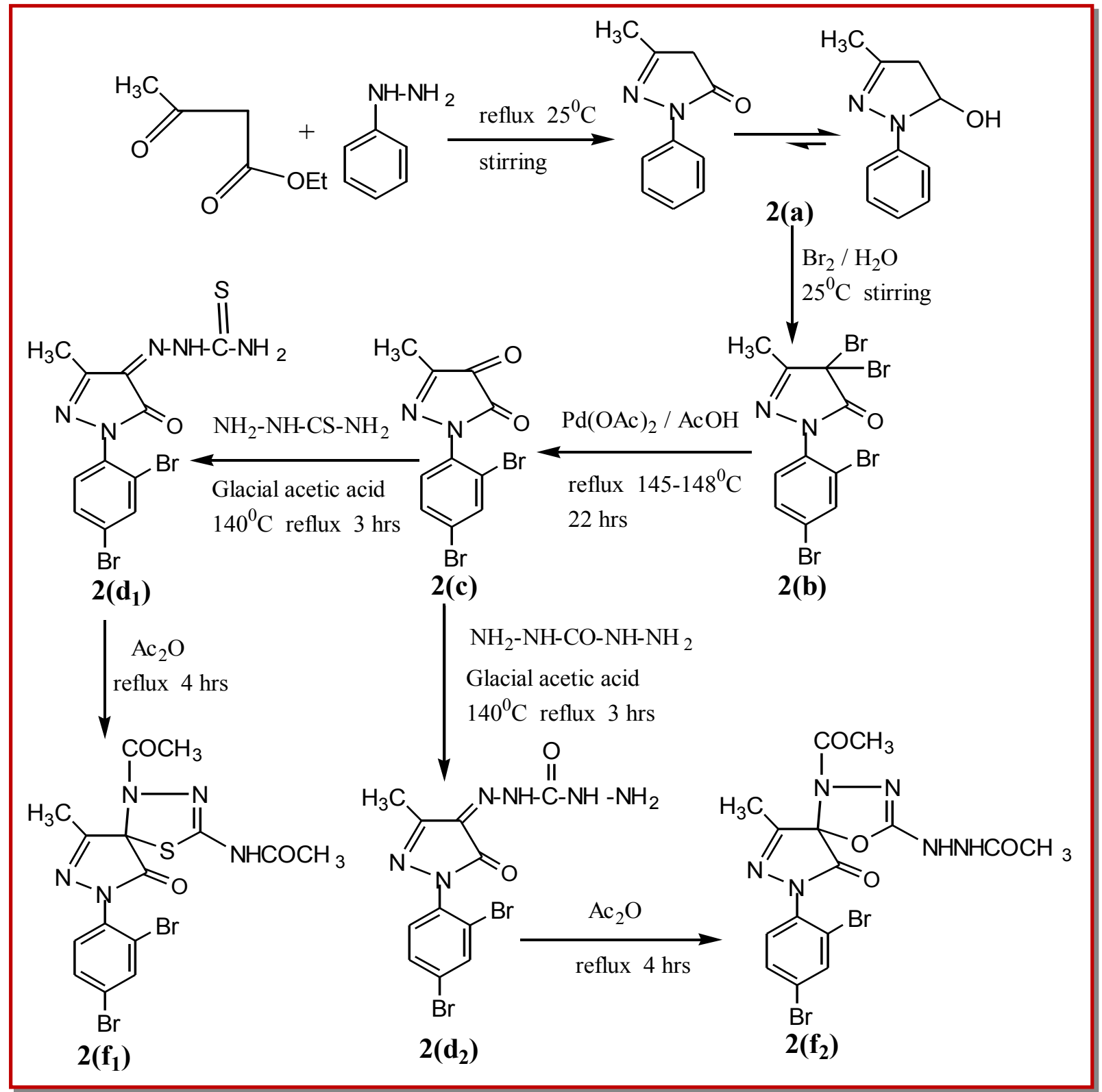

Scheme 1

Structurally both isatin (A) and pyrazoline-4, 5-dione (B) are similar:<smiles>O=C1Nc2ccccc2C1=O</smiles>

(A)<smiles>[R]N1N=C(C)C(=O)C1=O</smiles>

(B)
The cytotoxicity and anti-cancer activity of isatinthiadiazoline against cancer cell line was enhanced (Shaha et al., 1992). Similar activity from pyrazoline- dione is expected.

With this view two bromo-derivatives of $\Delta^{2}-1,3,4-$ thiadiazolines of pyrazolones $\left[\left(\mathbf{2}_{\mathbf{1}}\right)\right.$ and $\left.\left(\mathbf{2} \mathbf{f}_{2}\right)\right]$ were synthesized. The cytotoxicity activity of the synthesized compounds (Scheme 1) has been studied and reported.

\section{Materials and Methods}

A very important method for preparing of substituted pyrazole derivatives is by the reaction between $\beta$ diketoester and hydrazine or its derivative to form 5pyrazolone derivatives (Scheme 1). 


\section{Table I}

\begin{tabular}{|c|c|c|c|}
\hline \multicolumn{4}{|c|}{ Physical data of compounds, $2(a)$ to $2\left(f_{2}\right)$} \\
\hline $\begin{array}{l}\text { Com- } \\
\text { pounds }\end{array}$ & $\begin{array}{c}\text { Yield } \\
(\%)\end{array}$ & $\begin{array}{l}\mathrm{mp} \\
\left({ }^{\circ} \mathrm{C}\right)\end{array}$ & Nature of compounds \\
\hline 2(a) & 79 & 127 & $\begin{array}{l}\text { Pale yellow crystalline } \\
\text { solid }\end{array}$ \\
\hline 2(b) & 74 & 133-134 & $\begin{array}{l}\text { Pale yellow crystalline } \\
\text { solid }\end{array}$ \\
\hline 2(c) & 65 & 215-216 & Deep red crystalline solid \\
\hline $2\left(d_{1}\right)$ & 68 & $250-252$ & Deep red crystalline solid \\
\hline $2\left(d_{2}\right)$ & 82 & $255-256$ & Deep red crystalline solid \\
\hline $2\left(f_{1}\right)$ & 51 & $225-226$ & $\begin{array}{l}\text { Blackish-red crystalline } \\
\text { solid }\end{array}$ \\
\hline $2\left(f_{2}\right)$ & 72 & $225-226$ & $\begin{array}{l}\text { Blackish-red crystalline } \\
\text { solid }\end{array}$ \\
\hline
\end{tabular}

Following the method, substituted pyrazole derivative 3-methyl-1-phenyl-2-pyrazoline-5-one 2(a) was synthesized by condensation reaction of ethyl acetoacetate with phenyl hydrazine. Bromo-derivative substituted pyrazolone 4,4-dibromo-3-methyl-1-(2', 4 '-dibromobenzene)-2-pyrazoline-5-one, 2(b) was obtained by bromination of 2(a) followed by the reaction of bromine in water (El-Zohry et al., 1984). 3-Methyl-1-(2',4'-dibromobenzene)-2-pyrazoline-4,5-dione, 2(c) was produced by treating with lead acetate and glacial acetic acid. Schiff base, 3-methyl-(2',4'-dibromophenyl)-2-pyrazoline-4-thiosemicarbo-hydrazone-5-one, $\mathbf{2}\left(\mathbf{d}_{\mathbf{1}}\right)$ and 3methyl-(2',4'-dibromophenyl)-2-pyrazoline-4carbohydrazone-5-one, $\mathbf{2}\left(\mathbf{d}_{2}\right)$, were obtained by simple condensation reaction of substituted pyrazole-4,5-dione 2(c) with thiosemicarbazide and semicarbazide respectively in glacial acetic acid.

Fresh acetic anhydride (Kubota et al., 1980) (4 mL) was added to the stirred solution of 3-methyl-(2',4'-dibromophenyl)-2-pyrazoline-4-thiosemicar-bahydrazone-5one $2\left(\mathrm{~d}_{1}\right) \quad(90 \mathrm{mg}, 219 \mathrm{mmol})$ or 3-methyl-(2',4'dibromophenyl)-2-pyrazoline-4-carbohydrazone-5-one, $2\left(\mathbf{d}_{2}\right),(90 \mathrm{mg}, 219 \mathrm{mmol})$ in $4 \mathrm{~mL}$ acetic acid. The reaction mixture was refluxed for 4 hours at $118-120^{\circ} \mathrm{C}$. When the reaction was completed (by TLC monitoring), the reaction mixture was cooled at room temperature and the cooled mixture was poured into water. The resulting precipitate was collected by filtration with sintered glass crucible and recrystallized from methanol to give deep blackish-red needles of 5-spiro[-3-methyl(2', $4^{\prime}$-dibromophenyl)-2-N-acetyl- $\Delta^{2}-1,3,4$-thiadiazoline, 2(f $\left.\mathbf{f}_{1}\right)$ and 5-spiro[-3-methyl-(2',4'-dibromophenyl)-2-Nacetyl- $\Delta^{2}-1,3,4$-diazoline, $\mathbf{2}\left(\mathbf{f}_{2}\right)$ respectively. The products $\mathbf{2}\left(\mathbf{f}_{\mathbf{1}}\right)$ and $\mathbf{2}\left(\mathbf{f}_{2}\right)$ were blackish-red crystalline solid, soluble in $\mathrm{CH}_{3} \mathrm{OH}$, acetone and DMSO and were characterized by recording m.p., IR and NMR spectra. The melting points and yields of the compounds 2(a) to $\mathbf{2}\left(\mathbf{f}_{2}\right)$ are given in Table I.

All melting points were recorded by thin disk method on a "Fischer Johns" electrothermal melting point apparatus and are not corrected. Infrared spectra were recorded on DR-8001, SHI-MADZU FT-IR spectrophotometer as a solid, which was finely grounded in a small agate mortar with a drop of nujol (liquid hydrocarbon) as a mull and also in $\mathrm{KBr}$ disk. ${ }^{1} \mathrm{H}-\mathrm{NMR}$ spectra were measured by WP 400-NMR spectrometer, deuterated solvents such as dimethylsulphoxide (DMSO- $\mathrm{d}_{6}$ ) was used as solvents and the chemical shifts were quoted as $\delta$-value relative to tetramethyl silane (TMS, $\delta=\mathrm{O}$ ) as an internal standard. The purity of compounds was checked by TLC on silica gel plates and iodine was used as a visualizing agent.

\section{Brine shrimp lethality bioassay}

Because of the continuing interest of pyrazole derivatives (Islam et al., 2001) cytotoxicity investigation on the newly synthesized compounds was conducted by brine shrimp lethality bioassay (Solis et al., 1997). Brine shrimp (Artimea salina) lethality is a recent development in the bioassay for the bioactive compounds. Brine shrimp assay has advantage of being rapid (24 hours), inexpensive and simple (e.g., no aseptic technique is required). It easily utilizes a large number of organisms for statistical validation and requires no special equipment and a relatively small amount of sample is sufficient. Furthermore, it does not require animal serum, as it is needed for determination of cytotoxicities (Shaha et al., 1992).

Brine solution was prepared by dissolving with stirring of $20 \mathrm{gm}$ of sea salt ( $\mathrm{NaCl}$, non-ionized) in one liter of tap water and then filtered off to get a clear solution. 1 gm of brine shrimp egg per liter was taken in a beaker $(2,000 \mathrm{~mL})$ and The $\mathrm{pH}$ was adjusted to 8.5 with $0.1 \mathrm{M}$ $\mathrm{Na}_{2} \mathrm{CO}_{3}$ (Sigma-Aldrich) and temperature was $27-30^{\circ} \mathrm{C}$. Natural or artificial light (at night) was required and constant oxygen supply was carried out by bubble pump machine. The brine shrimps were hatched after one day and then aeration was stopped; hatching solution was allowed to settle for $20 \mathrm{~min}$. The aggregated shrimp was then collected in another beaker and rinsed with fresh water and applied for testing. $1.6 \mathrm{mg}$ of each compound in a sample vial was weighed by an analytical balance. Then $1.6 \mathrm{~mL}$ of DMSO were added to each vial and vigorously shaken to prepare stock solution. 5 $\mathrm{mL}$ of sea water was given in each test tube. With the help of micropipette specific volumes of samples were transferred from the stock solution to the test tube to get the final sample concentration of 33, 99 and 132 ppm. Then 10-20 brine shrimps, immediately germi- 


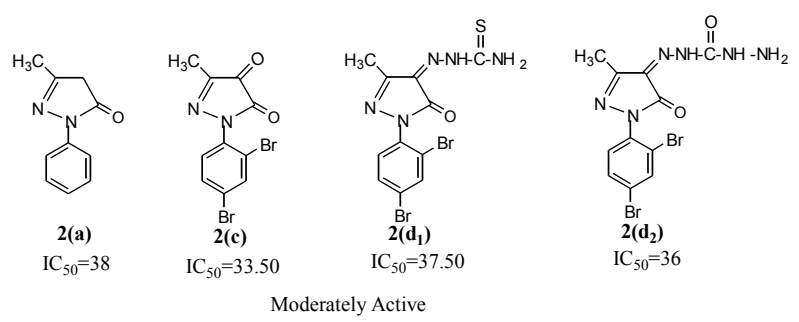

nated from brine shrimp eggs, were placed in each test tube. After 1, 2, 3 and 4 hours, the test tubes were observed and the number of survived nauplii in each test tube was counted and results were noted. From this, the percentage of lethality of brine shrimp nauplii was calculated at each concentration for each sample.

The cytotoxicity activity of the synthesized compounds was measured by $\mathrm{IC}_{50}$ on brine shrimp at different concentrations (33, 99 and $132 \mathrm{ppm})$. The citotoxicity of the compounds were evaluated by plotting the percentage of lethality of brine shrimp nauplii versus $\mathrm{H}_{3} \mathrm{C} \quad \mathrm{Br}$ doses (in ppm) of the synthesized $>\quad{ }^{\mathrm{Br}}$ compounds. It is expressed by $\mathrm{IC}_{50}$. The - $\lambda_{0} \mathrm{IC}_{50}$ of an agent is the doses, which will $\mathrm{Br}$ kill, or inactivate $50 \%$ of the test animal. ${ }^{\mathrm{Br}} \mathrm{IC}_{50}$ is inversely proportional to the toxicity of a compound, i.e. lower is the $\mathrm{Br} \quad \mathrm{IC}_{50}$, higher is the activity.

$\mathrm{IC}_{50}=19.5$, Highly active

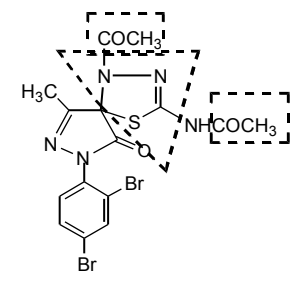

$2\left(f_{1}\right)$

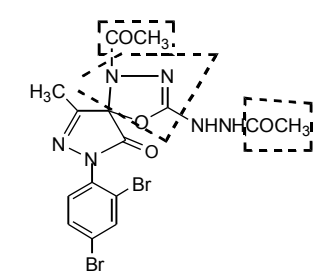

$2\left(f_{2}\right)$
$\mathrm{IC}_{50}=19.5$, Highly active

$\mathrm{IC}_{50}=20$, Highly active

\section{Results and Discussions}

Six bromo derivatives $\left(2 \mathbf{b}-\mathbf{2 c}, \mathbf{2} \mathrm{d}_{1-}-\mathbf{- 2} \mathrm{d}_{2}, \mathbf{2} \mathbf{f}_{1}-\mathbf{2} \mathbf{f}_{2}\right)$ of $3-$ methyl-1-phenyl-2-pyrazoline-5-one (2a) have been successfully synthesized with moderate to high yields (51-82\%). These newly synthesized bromo derivatives were characterized on the basis of physical properties as well as the spectral data analysis. The reaction pathways have been shown in Scheme 1. Two heterocyclic moieties consisting of two nitrogen atoms and other one with two nitrogen atoms along with a sulfur and another with two nitrogen atoms with oxygen have been judiciously chosen in order to get enhanced cytoxicity.
The $\mathrm{IC}_{50}$ of the synthesized compounds were determined by brine shrimp lethality bioassay and the results are shown in Table II. On the basis of these results the structure activity relation has been found out. Compounds 2(a), 2(c), 2( $\left.\mathbf{d}_{1}\right)$ and $2\left(\mathbf{d}_{2}\right)$ exhibit moderate cytotoxic properties.

Compound 2(b) having four bromine atoms shows better cytotoxicity property (Uddin, 2000).

Compounds $\mathbf{2}\left(\mathbf{f}_{1}\right)$ and $\mathbf{2}\left(\mathbf{f}_{2}\right)$ show better cytotoxic property (Uddin, 2000) than the corresponding Schiff base $\mathbf{2}\left(\mathbf{d}_{1}\right)$ and $\mathbf{2}\left(\mathbf{d}_{2}\right)$. This result provides that acetyl groups $\left(-\mathrm{COCH}_{3}\right)$ and the 1,3,4-thiodiazoline moieties are very important in producing cytotoxic activity. In other words, cyclization of thiosemicarbazone/semicarbazones enhances cytotoxic activity.

This enhanced cytotoxicity activity of thiodiazoline ring system is also observed in other system like isatin (Shaha et al., 1992).

The $\mathrm{IC}_{50}$ values of pyrazole derivatives having two nitro groups (Uddin, 2000) and two bromo groups at 2',4'positions of benzene ring in series 1 and 2 respectively are compared in Table III.

From the above mentioned values of $\mathrm{IC}_{50}$, it has been observed that pyrazole derivatives $\mathbf{1}(\mathbf{b}), \mathbf{2}(\mathbf{b}) ; \mathbf{1}(\mathbf{f}), \mathbf{2}\left(\mathbf{f}_{2}\right)$ in respective series exhibited high cytotoxic effect and the rest compounds $\mathbf{1}(\mathrm{a}), \mathbf{2}(\mathrm{a}) ; \mathbf{1}(\mathrm{c}), \mathbf{2}(\mathrm{c}) ; \mathbf{1}(\mathrm{d}), \mathbf{2}\left(\mathrm{d}_{1}\right)$ in relevant series performed modest cytotoxic activity.

In case of variable cytotoxic effects of pyrazole derivatives it would be realized that different functional groups or substituents at position-4 on pyrazole ring were responsible for execution of the different $\mathrm{IC}_{50}$ values. When two bromo groups were present at position- 4 on the pyrazole ring, both bromopyrazole derivatives 1(b), 2(b) in respective series showed higher activity (Uddin, 2000). In similar way if compounds 1(f) and $\mathbf{2}\left(\mathbf{f}_{2}\right)$ are considered, these compounds revealed better cytotoxic activity on account of having the acetyl group $\left(-\mathrm{COCH}_{3}\right)$ and 1,3,4-thiadiazoline moiety (Shaha et al., 1992; Islam et al., 2001) after cyclization of thiosemicarbazone. Compounds 1(a), 2(a); 1(c), 2(c); 1 (d), $2\left(\mathrm{~d}_{1}\right)$ in related series possessing methylene $\left(>\mathrm{CH}_{2}\right)$, carbonyl $(>\mathrm{C}=\mathrm{O})$ and imine $(>\mathrm{C}=\mathrm{N}-)$ functional groups correspondingly on position- 4 of pyrazole ring (Shaha et al., 1992; Islam et al., 2001) would be liable to demonstrate their moderate cytotoxic effect.

In the present study, the synthesized compounds were investigated for their property as cytotoxic agents by brine shrimp lethality bioassay. Among them the compounds $\mathbf{2}(\mathbf{b}), \mathbf{2}\left(\mathbf{f}_{1}\right)$, and $\mathbf{2}\left(\mathbf{f}_{2}\right)$ were highly active according to $\mathrm{IC}_{50}$ values 19.5, 19.5 and $20 \mathrm{ppm}$ respectively. The rest of compounds $2(a), 2(c), 2\left(d_{1}\right)$ and 


\section{Table II}

The result of cytotoxicity activity (IC 5024 hours) of synthesized compounds against brine shrimp

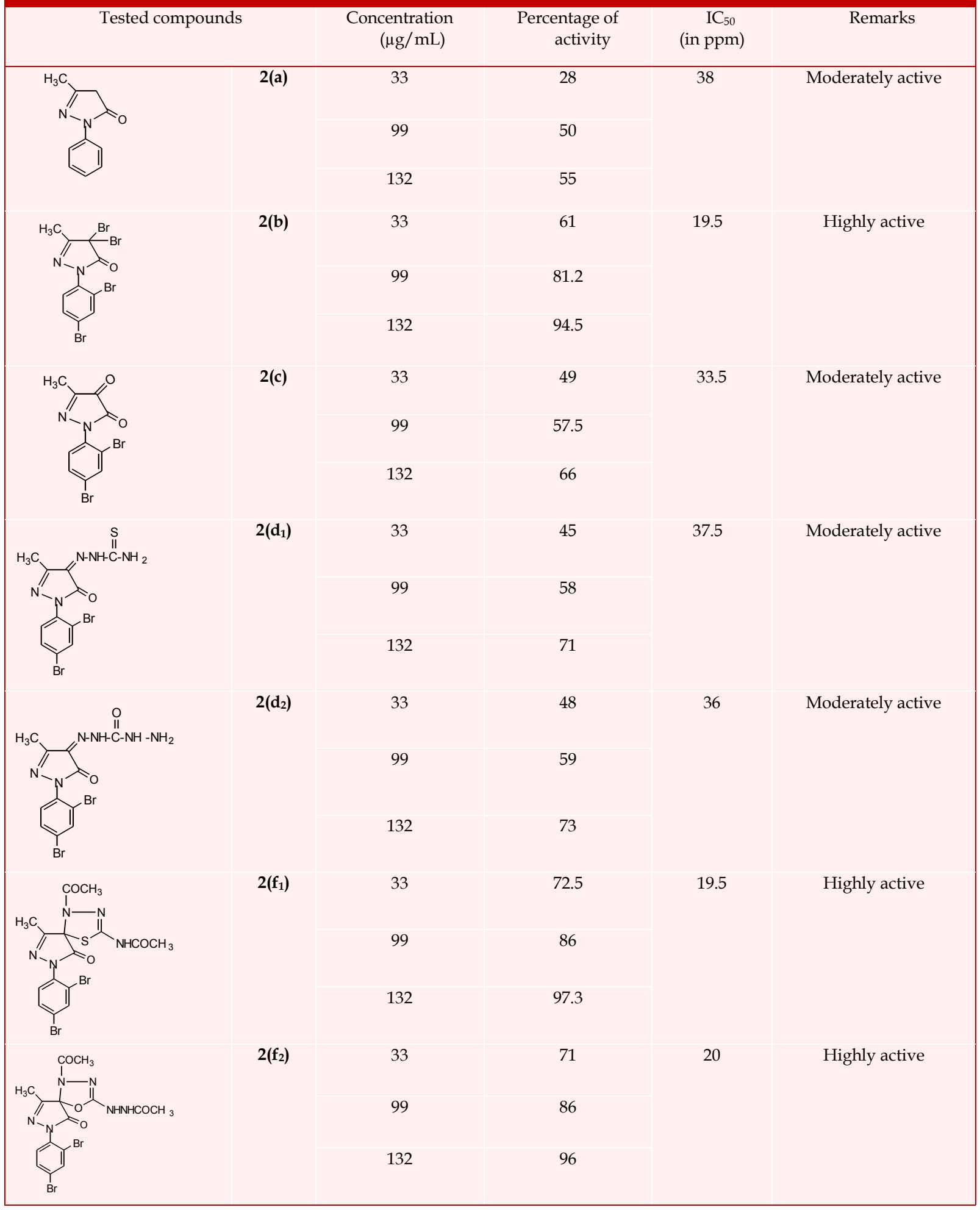

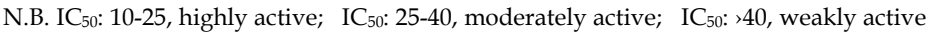

2(d $\left.\mathbf{d}_{2}\right)$ having $\mathrm{IC}_{50}$ values $38,33.5,37.5,36,37.5$ and 36 ppm in that order, were moderately active. 


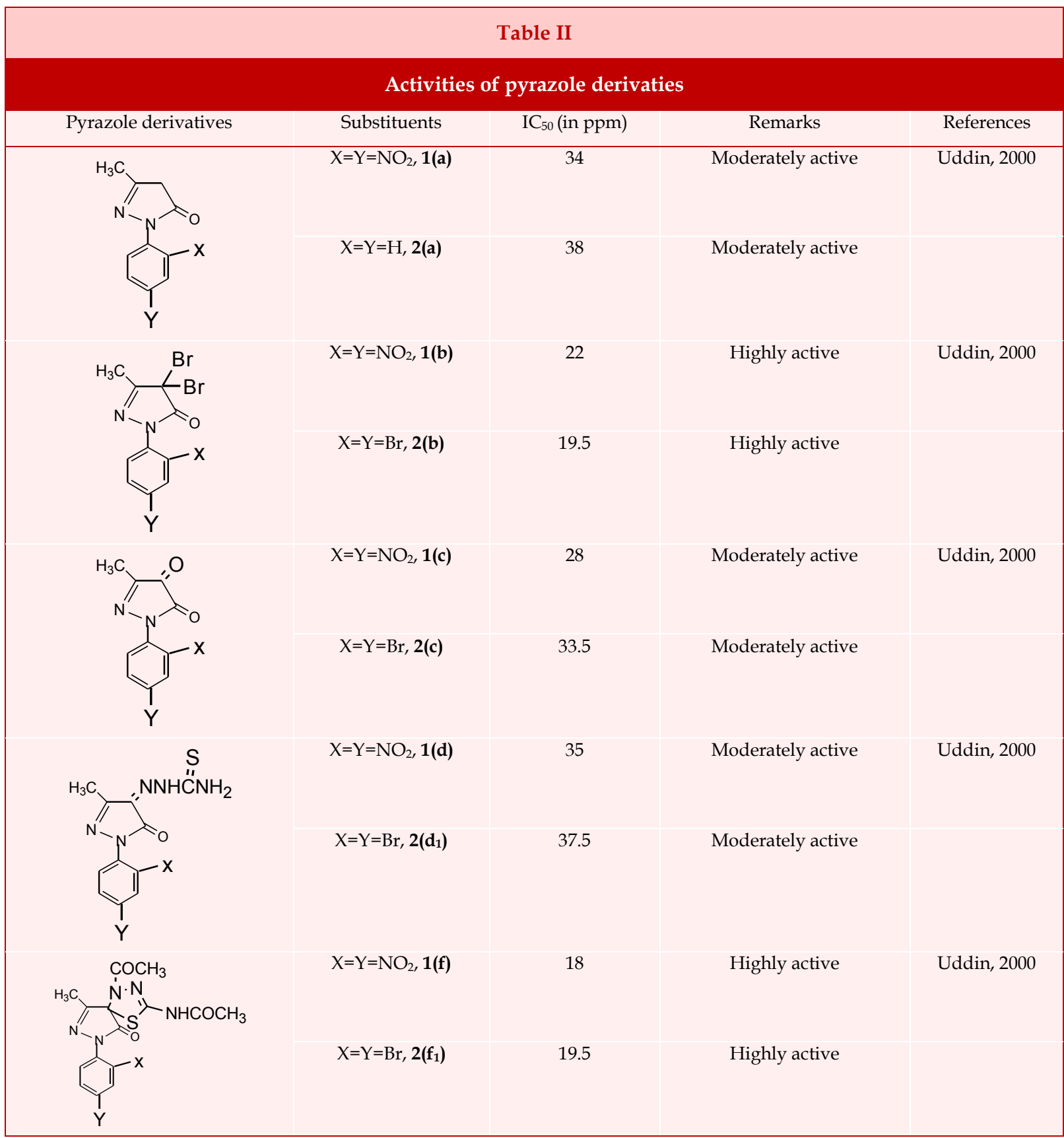

\section{References}

Badawey ESAM, El-Ashmawey IM. Non-steroidal antiinflammatory agents- Part 1: Anti-inflammatory, analgesic and antipyretic activity of some new 1-(pyrimidin-2-yl)-3pyrazoline-5-ones and 2-(pyrimidin-2-yl)-1,2,4,5,6,7hexahydro-3H-indazol-3-ones. Eur J Med Chem. 1998; 33: 349-61.

El-Zohry MF, Younes MI, Metwally SA. Synthesis and some reactions of 3-methyl-2-pyrazolin-4,5-dione. Synthesis 1984; 972.

Finar IL. Stereochemistry and the chemistry of natural products. $5^{\text {th }}$ ed. Singapore, Longman, 1994, pp 608-11.

Gürsoy A, Demirayak S, Çapan G, Erol K, Vural K. Synthesis and preliminary evaluation of new 5-pyrazolinone derivatives as analgesic agents. Eur J Med Chem. 2000; 35: 359-64.

Islam MR, Khayer K, Ahmad MM. Synthesis of 3methylpyrazoline-5-one and its 3,3-dimethyl-5,5-ethene-bis-2 -pyrazoline-4,4-dione, substituted cyclic tri-azothione and Nacetylated derivatives. J Bangladesh Chem Soc. 2001; 14: 33.

Islam MR, Muhsin M. Synthesis of 5-chloroisatin-6,7dimethylisatin and their carbohydrozone and $\Delta^{2}-1,3,4-$ 
oxadiazoline and their cytotoxicity studies. Bangladesh J Pharmacol. 2007; 2: 7-12.

Islam MR. Cytoxicity studies on $\Delta^{2}-1,3,4$-thiadiazoline heterocycles. Proceedings Bangladesh Chem Congress. 2004, 1LC5, p 157.

Kubota S, Ueda Y, Fujikane K, Toyooka K, Shibuya M. Synthesis of 4-acyl-2-(acylamino)-.DELTA.2-1,3,4thiadiazolines and 4-acyl-2-amino-.DELTA.2-1,3,4thiadiazolines by acylation of thiosemicarbazones. J Org Chem. 1980; 45: 473-77.
Shaha GC, Khayer K, Islam MR, Chowduri MS. Synthesis of thiocarbohydrazide, some thiocarbo-hydrazoenes and their cyclized products as probes for pharmalogical studies. Indian J Chem. 1992; 31B: 547.

Solis PN, Wright CW, Anderson MM, Gupta, Phillipson JD. A microwell cytotoxicity assay using Artemia salina (brine shrimp). Planta Med. 1997; 59: 250-52.

Uddin MI. Synthesis and biological evaluation of some pyrazolone as anticancer agents. MSc Thesis, Jahangirnagar University, 2000. 